\title{
LOS GRUPOS DE INTERÉS \\ Y LA REGULACIÓN PÚBLICA DEL MERCADO \\ DE ALCOHOLES EN ESPAÑA (1887-1936) *
}

\author{
JUAN PAN-MONTOJO \\ Universidad Autónoma de Madrid \\ y NÚRIA PUIG RAPOSO \\ Universidad Complutense de Madrid
}

\section{RESUMEN}

En este trabajo se analiza la actuación de grupos de interés en el mercado de los alcoholes entre 1887 y 1936 . La investigación pretende responder a la pregunta de si los grupos de presión de este sector agroindustrial tuvieron un papel relevante en la configuración de la política económica -proteccionista- que guió, o inhibió, el crecimiento de la economia española durante la Restauración. Para hacerlo se ha reconstruido, a partir de la documentación de las comisiones parlamentarias y de las publicaciones y escritos de los propios grupos, su interacción con las instancias politicas y administrativas. Se concluye que 1 . Los grupos de presión gozaron de una gran autonomía respecto a los intereses, extraordinariamente heterogéneos, del sector, 2. El Parlamento se mostró incapaz de establecer prioridades entre los intereses en pugna; y 3 . El proceso legislativo tendió a vaciar de contenido las principales propuestas de representantes del sector y no llegó a definirse una política alcoholera.

\section{ABSTRACT}

This paper analizes the performance of interest groups in the Spanish alcohol market between 1887 and 1936. The research addresses the question of the impact of these agroindustrial interest groups in the making of - protective- economic policies during

* Una primera versión de este trabajo fue presentada en el Seminario de Historia Económica de la Universidad Autónoma de Madrid y la Universidad Complutense de Madrid en mayo de 1993. Agradecemos especialmente los comentarios críticos de James Simpson. A Manuel Martín, que mostró gran interés desde el principio por este trabajo, le debemos ideas y sugerencias que esperamos haber reflejado en el texto. Por último, agradecemos sus indicaciones a los evaluadores anónimos de la Revista de Historia Económica. 
the Restauration. In order to answer this question, we have reconstructed their interaction with political and administrative agencies, on the basis of both the published documents of the groups and associations, and the records of the parliamentary committees. The main conclusions are: 1 . Pressure groups remained very autonomous with regards to the extremely heterogeneous interests of the sector, 2 . The Parliament proved unable to establish priorities among the conflicting interests; and 3. The lawmaking process ignored the main proposals and did not produce an alcohol policy.

\section{INTRODUCCIÓN}

En la historiografía económica española no ha sido raro el enfrentamiento entre «agraristas» e «industrialistas». Es éste el caso del debate, persistente, entre los que interpretan el atraso económico del país desde el lado de la oferta (pues faltaron una buena dotación de recursos y una adecuada gestión de los empresarios) y los que lo hacen desde el lado de la demanda (ya que ésta, condicionada por el lento desarrollo del sector agrario, no fue capaz de estimular el crecimiento industrial) ${ }^{1}$. Al calor de este debate se asiste, periódicamente, a nuevas interpretaciones de la política económica desplegada por el Estado durante el período comprendido entre los años treinta del siglo pasado y el estallido de la guerra civil en $1936^{2}$. Los autores más críticos con el proteccionismo -que son los que mayor presencia han tenido en la bibliografia de estos años- apuntan a que los gobiernos atendieron (hasta 1891 o 1906) a la agricultura y (desde 1891 o 1906) a la industria, reservando para la producción nacional el modesto, pero cómodo, mercado interior. El Estado respondió tanto a las presiones de los grandes grupos de interés (cerealistas, vitivinicultores, siderúrgicos y algodoneros), de los que era «cautivo», como a las doctrinas que propugnaban la exportación como motor de crecimiento o la protección a las industrias nacientes, pero hizo pagar en cualquier caso a los consumidores la falta de competitividad de la economía y contribuyó al atraso relativo del crecimiento económico español.

La mayoria de los historiadores que se han ocupado de este tema en fechas recientes, han supuesto que los intereses económicos a corto plazo de los agentes eran evidentes y que éstos podían en determinadas circunstancias or-

1 Prados (1988) y Nadal (1986) son ejemplos relevantes de una y otra postura. Nos parecen de gran interés para este debate las propuestas teóricas y observaciones críticas presentadas en Nadal y Sudrià (1993). Una posición intermedia es la expresada por Tortella (1994), que atribuye el atraso económico español a razones geográficas (la geografía como obstáculo a la dífusión de la «revolución agricola») y razones culturales (la cultura «meridional» como freno a la modernización).

2 Serrano Sanz (1987), Fraile Balbin (1991), Palafox (1991), por citar sólo algunos. 
ganizarse sin demasiadas dificultades, por lo que han dedicado una atención mínima, o nula, al análisis, o siquiera a la identificación, de los grupos de presión españoles y de la representación de intereses ${ }^{3}$. Así, por ejemplo, en la obra de Fraile se señala, de acuerdo con la teoría olsoniana ${ }^{4}$, que la formación e influencia de los grupos de presión dependen estratégicamente de una elevada concentración industrial y geográfica de las empresas del sector en cuestión, por lo que se hace referencia preferente a los siderúrgicos vascos y a los textiles catalanes, dejando en un segundo plano a unos supuestos representantes de la «trilogía mediterránea». Además, la relación entre grupos de interés, representación, clase política y Administración queda resuelta mediante hipótesis vagas, sin ningún análisis de cómo eran o de cómo podían ser éstas. La modelización in abstracto de unos mecanismos similares a los de los mercados impersonales y la identificación presentista y simplificadora de los comportamientos de funcionarios y politicos, sirven de base para una teoría general de la captura del Estado.

A nosotros este enfoque nos parece poco convincente. Dudamos de que 1) la constitución de grupos de interés y la explicación de su acción sea analizable exclusivamente en términos de coste-beneficio individual y agregado, y número y dispersión de sus integrantes potenciales 5; 2) la política económica (gestada en sus principios generales en las dos cámaras por los políticos de la Restauración, y desarrollada y aplicada por las instancias gubernamentales y administrativas) respondiera con exactitud y de forma permanente a la mera suma de intereses sectoriales políticamente hegemónicos; 3) la Administración no definiera un interés público, irreductible a las demandas en un precario mercado de votos o a las aspiraciones de los funcionarios, por más que estuviera mediatizado por unas y otras. Creemos, por último, que es necesario un

3 Tal es el caso de Fraile, que no ha documentado la historia de ninguno de esos grupos de presión. El tema sigue interesando a historiadores como Cabrera (1983), del Rey (1992), Arana (1988) o Escudero (1994).

4 Olson (1977), especialmente partes I y II, y Olson (1986), capitulo II.

"La constitución de organizaciones de representación de intereses es un proceso que se ve profundamente condicionado por la existencia previa de redes relacionales cuya lógica de funcionamiento no está guiada por la búsqueda individual de fines «racionales» de carácter específico -especificidad que permitiria la determinación de los beneficios y de los costes, y por tanto haría viable al análisis coste-beneficio--. Por otra parte, la "presión» pública de los grupos organizados pasa por estrategias de redefinición y globalización de sus aspiraciones, que al margen de que sean o no operaciones publicitarias, de ocultamiento de los objetivos reales (Stigler, 1975), implican necesariamente transformaciones de sus contenidos (Meny y Thoenig, 1992; pp. 121122). En el campo de la historiografía, véanse los excelentes estudios de Banti (1990) y Malatesta (1989), con una sugerente aplicación de la metodología de redes al estudio de la burguesía de Plasencia (Piacenza en Italia) y de sus plataformas asociativas, en el primer caso, y un excelente estudio global de la representación de intereses en el valle del Po, en el segundo. 
estudio descriptivo como paso previo a la formulación de hipótesis sobre los mecanismos de la demanda, génesis y funcionamiento de la regulación en contextos políticos y sociales concretos. Sólo a partir de aquí puede analizarse en términos económicos la acción de los grupos de interés.

En este articulo, nuestro banco de pruebas es el sector alcoholero en sentido amplio, que nos ha parecido muy adecuado por cuanto que se trata de una actividad tanto agraria como industrial. Este sector, que es uno de los peor conocidos de nuestro pasado industrial, presenta tres peculiaridades: la de su decisiva y precoz regulación estatal; la de comprender unidades productivas con tamaños, técnicas, actividades y objetivos muy diversos - estructuras de costes heterogéneas - y un producto final muy homogéneo; y la de su alto grado de dispersión geográfica e importante volumen de negocios. El interés de los poderes públicos por el alcohol quedó pronto reflejado en una legislación y reglamentación prolijas y cambiantes, además de en varios cientos de miles de expedientes fiscales. En su origen y en sus formas estuvieron implicados muchos de los que participaban en el negocio del alcohol, que hicieron llegar sus aspiraciones a diputados, senadores, funcionarios y ministros. A su vez, cada medida adoptada sirvió de estímulo a la constitución de «grupos de presión», que se formaron y actuaron a pie de fábrica, entre los vitivinicultores, azucareros y alcoholeros, y entre los clientes directos e indirectos de las alcoholeras: almacenistas, licoreros, perfumistas o taberneros. Aunque la mayor parte de los grupos distaron mucho de ser coherentes, y las alianzas que llegaron a fraguarse tuvieron una existencia difícil y breve, su actividad fue intensa. La gran incidencia en la agricultura del cultivo de la vid y de la remolacha -origen de las principales materias primas del alcohol-, aseguraron adicionalmente que la participación en los debates provocados por la organización del sector fuera muy amplia 6 .

La prensa, una amplia literatura de folletos y libros, las exposiciones a las Cortes y la documentación de las comisiones parlamentarias, han sido las fuen. tes de nuestro trabajo, que ha consistido en reconstruir el proceso a través del cual los diversos intereses se impusieron, o trataron de imponerse, a los poderes públicos, durante la fase de discusión parlamentaria. Hemos estructurado la exposición en cuatro secciones: una primera está dedicada a la presentación de los tres grandes sectores implicados en la cuestión de alcoholes (el alcoholero, la vitivinicultura y el azucarero) y su evolución a lo largo del período 1880-1936, en conexión directa con el curso de la legislación; la segunda re-

6 Mucho más que cualquier otro, con la posible excepción del que enfrentó a proteccionistas y librecambistas. 
construye el proceso de organización corporativa; la tercera trata de establecer las pautas de funcionamiento del Parlamento en los debates sobre alcoholes; la última sección es tanto un balance como una modesta reflexión acerca de las posibilidades y límites de la regulación pública del desarrollo agrario e industrial, en un escenario económico e institucional como el de la España liberal.

\section{LA INDUSTRIA ALCOHOLERA Y LOS VINOS Y AZÚCARES 7}

Hasta el siglo XIX, las regiones mediterráneas de Europa se beneficiaron de la abundante disponibilidad de vinos y subproductos de la vinificación (orujos, vinos inferiores, vinos torcidos) para destilarlos en rudimentarios alambiques. Los alcoholes y aguardientes ${ }^{8}$ que asi se obtenían se consumían en los lugares de origen y, de forma creciente, en el norte de Europa. De los países productores de aguardientes vínicos destacaba España, en particular Cataluña, cuyos espiritus conocieron a lo largo del Setecientos una época de esplendor, inundando los mercados europeos y coloniales y enriqueciendo a diversos grupos que participaban en su ciclo productivo y comercial. El viñedo no era sin embargo el único paisaje en el que florecía el aguardiente. En los dominios ultramarinos de dos grandes potencias coloniales, Gran Bretaña y Francia, y en las propias metrópolis, se destilaban desde el siglo xvil las melazas de caña de azúcar. El éxito del ron y de otros líquidos alentó la difusión, el crecimiento y el perfeccionamiento de esta actividad. En este contexto debe explicarse la aparición de los primeros alambiques modernos (continuos 9) y las primeras destilerias a gran escala, donde a partir de toda clase de materias fermentables se obtenían alcoholes cada vez más homogéneos y de más alto contenido alcohólico, que podían servir eventualmente para encabezar o enriquecer vinos y aguardientes vínicos. La transformación de la destilación trajo consigo una mayor complejidad en el negocio alcoholero, una mayor competencia en los mercados europeos y la creciente atención de las haciendas públicas, que veian en los destilados un prometedor articulo de renta.

7 Una exposición más detallada, en Puig Raposo (1994a y 1994b), desde el punto de vista de la industria alcoholera, y Pan-Montojo (1993 y 1994a), desde el de la vitivinicultura.

${ }^{8}$ La diferencia entre aguardientes y alcoholes es una cuestión de grado. Los primeros son liquidos de una graduación alcohólica inferior a los segundos (la frontera se ha tendido a situar históricamente entre los $60^{\circ}$ y los $70^{\circ}$ ) y suelen ser considerados como los únicos destinados directamente a la bebida. A su vez los aguardientes y los alcoholes se subdividen en diferentes tipos según su grado.

9 Frente a los discontinuos, los alambiques continuos eran aquellos que podían ser alimentados ininterrumpidamente, con el consiguiente ahorro energético. 
En la Peninsula Ibérica, el proceso de industrialización de la fabricación de alcoholes - vinicos en la práctica totalidad de los casos- tuvo lugar a lo largo del siglo XIX, como en el resto de Europa, y siguiendo de cerca los avances técnicos de la vecina Francia. Pero el proceso presentó especiales dificultades por múltiples razones: la pérdida de buena parte de los mercados coloniales; la creciente competencia de los fabricantes europeos; y la introducción de los cultivos de la caña y de la remolacha y la multiplicación de los ingenios y las destilerias anexas, capaces de producir un alcohol más homogéneo a un menor coste que el vínico. El entorno en el cual habrian de desenvolverse los productores de aguardientes vínicos se transformó así sustancialmente. Además, los intereses afectados por el alcohol presentaban en España ciertas peculiaridades. Los suministradores de materias primas, viticultores y remolacheros (pues la remolacha azucarera empezó a tener una presencia significativa desde finales de la década de 1880), traducían parcialmente en su enfrentamiento otras divisorias: agricultura tradicional frente a agricultura moderna, y pequeña explotación frente a gran explotación. En el seno de los fabricantes también se oponian los intereses de los vínicos (subdivididos a su vez por la escala y carácter de sus operaciones ${ }^{10}$ ) a los de los «industriales» (como se llamaba en toda Europa a los que empleaban para la destilación materias primas distintas al vino o los residuos vínicos), entre los que en España no había «artesanos» y sí, casi siempre, instalaciones fabriles, con altas dotaciones de capital fijo. Entre los vinicultores, fueran o no viticultores, revistió un carácter permanente la discrepancia entre los que pensaban en términos de suministradores de materia prima a los alcoholeros y los que lo hacian en términos de compradores de alcohol para fortalecer sus vinos, posiciones polares que reunieron distintos grados de adhesión según la coyuntura concreta del mercado vinícola. No debe extrañarnos pues que la Hacienda se fuera alejando de su natural función recaudadora (la imposición española sobre alcoholes era a finales del XIX, y siguió siendo en adelante, una de las más bajas de Europa) y asumiera el papel de árbitro del sector. Un sector que en la segunda mitad del siglo pasado se extendía por todo el país, se modernizaba lentamente, perdía año a año competitividad en el mercado internacional y en el que las voces de los grupos implicados (con la excepción de los consumidores) se hacian oir cada vez más.

El gran auge exportador de la vitivinicultura española desde 1877 , que fue ocasionado por la destrucción del viñedo francés por la filoxera y aprovecha-

10 No era desde luego idéntica la posición de los aguardenteiros gallegos que arrendaban sus servicios a los cosecheros en una actividad ambulante y de temporada, y la de los propietarios de fábricas de alcoholes que adquirían vinos o subproductos vínicos para la elaboración de aguardientes, licores o alcoholes. 
do mediante un convenio comercial hispano-francés que redujo radicalmente la protección arancelaria del Estado vecino, abrió las puertas a una modificación profunda de las posibilidades de las alcoholeras. El encarecimiento del vino y el crecimiento de la demanda de alcohol ofrecían, en efecto, vías claras de despliegue industrial. Pero esta «edad de oro» del vino, al sustentarse en una red de tratados internacionales que redujeron el nivel de protección del mercado interior, favoreció la entrada de alcoholes industriales extranjeros, fundamentalmente alemanes, y la paralización de muchas destilerias. La fortaleza de la demanda exterior generó fuertes subidas de los precios del vino en la década 1877-86, con lo que también se elevaron los costes del aguardiente vínico, abriendo un amplio hueco a las importaciones. Sin embargo, hacia finales de 1886 los precios del vino empezaron a caer de forma pronunciada, iniciándose la crisis vinícola que alteró por completo las perspectivas para la industria alcoholera.

La crisis estuvo más determinada por la multiplicación industrial de la mercancía vendida como vino - un producto que mediante la adulteración con agua, alcohol y colorante del vino probablemente superaba en casi un $50 \%$ a la cosecha real- que por la propia expansión del cultivo y de sus rendimientos físicos, y fue agravada, en 1892, por el cierre del mercado francés en medio de un general giro proteccionista de los países occidentales ${ }^{11}$. La falsificación dio origen a la llamada "cuestión de alcoholes», que acabó encontrando una solución transitoria en la exclusión del alcohol industrial extranjero mediante el recurso a un impuesto especial en 1888 y 1889 , que luego pasó al arancel en 1892. El cierre del mercado francés era más difícil de superar: no obstante los esfuerzos españoles, desde el 31 de enero de 1892 se terminaron las singulares condiciones que habian hecho de España y Francia prácticamente un único mercado vinícola y alcohólico.

La contracción de la demanda de vino natural fue seguida en los años 90 por un recorte en la oferta, motivada tanto por la filoxera que invadió la Península como por la reducción de los incentivos a la falsificación, con lo que se atenuaron las dimensiones de los excedentes. Sin embargo, a partir de 1899 la «crisis vinícola» se instaló como realidad permanente, aunque la situación sólo revistiera dimensiones verdaderamente criticas en algunas regiones del pais. Las dificultades en la venta del vino fueron atribuidas a la saturación del mercado internacional y al fraude. Así, en años de buena cosecha, los precios caían por la falta de exportaciones y, en años de mala, la sofisticación de los caldos ponía un techo al alza de las cotizaciones. Pese a que las menguadas

11 Pan-Montojo (1994a y 1994b). 
producciones del quinquenio 1910-15 -y el crecimiento de la demanda motivado por las excepcionales condiciones económicas vinculadas a la Gran Guerra- vinieron a limar las tensiones, en los años 20 reapareció el fantasma de la sobreproducción. Con él recibió un nuevo impulso un problema cuyos datos básicos (tanto desde la perspectiva de la estructura sectorial, como desde la de las políticas adoptadas) estaban presentes a principios de siglo.

La gran diferencia de la nueva «cuestión de alcoholes» de las tres primeras décadas de siglo con respecto a la planteada a finales de los años 1880 es que al amparo de un arancel prohibitivo ya se habian desarrollado plenamente las destilerías industriales, que trabajaban con los residuos de otra agroindustria de nuevo cuño, la azucarera, e incluso con cereal importado. La mayoría de las cerca de dos mil «fábricas de aguardiente» que a mediados del Ochocientos funcionaban legalmente en el territorio español eran prolongaciones modestas (y estacionales) de explotaciones agrarias que utilizaban como materia prima productos vitícolas. Hacia 1900 - cuando la importancia de la destilación había crecido dentro de la actividad fabril española - aparecian registradas 2.728 fábricas de aguardientes vínicos y 777 de alcoholes industriales, cuyas capacidades de producción y nivel técnico habian mejorado, en algunos casos, considerablemente. Es decir, que en 1900 el alcoholero se había convertido en un sector complejo y en parte autónomo de la vitivinicultura. Para entonces, los principales problemas de la industria tomada en su conjunto eran dos: abastecerse de materias primas - para que los modernos aparatos de destilación continua pudieran funcionar- y encontrar salida a sus productos. El primer problema dependia de los resultados de las campañas del vino y el azúcar de cada año. El segundo era, en épocas de producción normal, irresoluble, pues, si la capacidad de la industria española era de unos 2,5 millones de hectolitros al año, el consumo interior fluctuaba alrededor del medio millón de hectolitros, y los mercados exteriores parecían díficiles de reconquistar. A las demandas de regulación que nacían de las perspectivas vitivinicolas de la «cuestión de alcoholes», se sumaron por tanto las formuladas por las industrias crecidas en los años 90 y a lo largo del primer tercio del siglo XX.

Para intervenir en el sector alcoholero, los poderes públicos habian desarrollado tres tipos de instrumentos: arancelarios, sanitarios y fiscales. Tras la exclusión del mercado de los alcoholes extranjeros en 1892 y de los antillanos en $1898^{12}$, y dada la ineficacia de los controles sanitarios de los alimentos, las limitaciones técnicas de los análisis químicos de la época y el rechazo general

12 En realidad, la caida de las importaciones de azúcares y destilados antillanos se inició con el estallido del conflicto colonial a mediados de la década. 
de las soluciones universales como la desnaturalización ${ }^{13}$ o el monopolio de producción, los tres instrumentos se redujeron a uno solo: la fiscalidad. El recurso a ésta se veía además favorecido por la inadecuación del impuesto de consumos sobre especies determinadas a la estructura económica desarrollada en la segunda mitad del xIx, y por el rechazo social y político de dicha figura, que forzaba a la búsqueda de nuevas vías de imposición indirecta sustitutoria. Estos elementos, y la rentabilidad de las contribuciones sobre alcoholes en otros países, convirtieron en prácticamente inevitable la consideración del alcohol como un artículo de renta con un potencial recaudatorio muy amplio e infrautilizado. La intervención fiscal de la producción de alcoholes difícilmente podía aspirar a la neutralidad, dada la heterogeneidad de los tejidos productivos, los variados usos del alcohol y las demandas y compromisos políticos de partida, así como sus rápidas modificaciones temporales. Por tanto la fiscalidad $-\mathrm{y}$ una fiscalidad necesariamente regulatoria- ocupó el centro de la escena.

\section{LOS GRUPOS DE INTERÉS Y LA LEGISLACIÓN FISCAL}

Alrededor del impuesto de alcoholes se constituyeron en efecto grupos de interés diversos. Inicialmente su actuación se canalizó a través de las instituciones existentes (juntas y consejos, cámaras, sindicatos o gremios) -en su mayoría integradas en la Administración o sometidas a su tutela - o por medio de alianzas ad-boc de notables, además de recurriendo a los cauces de mediación personalizada que ofrecía el sistema político. El movimiento decimonónico tuvo un alcance local y una actividad coyuntural y discontinua, y en él lograron un destacado peso los viticultores. Por el contrario, con el siglo xx se asistió a un proceso de separación de la representación de intereses respecto al Estado, con el desarrollo de asociaciones sectoriales como las federaciones agricolas y la multiplicación de propuestas de agrupar a las clases productivas frente a «la política». Por último, los años de mutaciones estructurales asociados a la Gran Guerra abrieron paso a la fragmentación de la representación de intereses y a la ampliación de sus ámbitos de cobertura en todas las direcciones.

La primera movilización de los fabricantes de alcohol y aguardientes tuvo lugar a comienzos de los años ochenta del siglo pasado. El temor a verse discriminados fiscalmente frente a los tradicionales destiladores de vino y orujo

13 Por desnaturalización se entendia la adición de sustancias (colorantes o sabores especiales) a los alcoholes industriales, que hicieran imposible su empleo para usos de boca, garantizando asi el cumplimiento de la norma que impedia fortalecer el vino con alcoholes no vínicos. 
llevó pronto a los nuevos fabricantes de alcohol industrial a solicitar protección para esta «industria naciente» ${ }^{14}$. Su escaso peso hizo ociosas sus protestas y durante más de una década, mientras duró el auge de las exportaciones vinícolas, los alcoholes industriales extranjeros invadieron el mercado.

Entre 1887 y 1892, cuando la bonanza había dejado paso a la crisis en la vitivinicultura, fueron los representantes de distintos intereses (pequeños cosecheros, bodegueros, mayoristas, exportadores) los que protagonizaron un conjunto de movimientos y contramovimientos - canalizados por todas las instituciones oficiales existentes y por las vías de representación caciquil ${ }^{15}$, , que se enfrentaron en lo relativo a la conveniencia de excluir los alcoholes no vínicos de los usos de boca y, por otra parte, a la reserva del mercado nacional para los alcoholeros nacionales. Esta fase se saldó en 1893 (tras la redacción de una primera Ley en 1888, una segunda en 1889 y una tercera en 1892) con un nuevo diseño legal del mercado. Por una parte se consolidó un régimen fiscal que discriminaba a los alcoholes industriales mediante un gravamen notablemente superior al de los alcoholes obtenidos del vino, si bien en la práctica el sistema diseñado acabó asegurando amplias vías de elusión y fraude a las escasas fábricas de alcohol industrial ${ }^{16}$. Por otra parte se dio forma definitiva a un régimen arancelario que impedía la entrada de alcoholes extranjeros. Tras una década de importaciones masivas de alcohol, los alcoholeros industriales tenian una posición muy débil, y no protagonizaron ningún movimiento abierto de defen-

${ }_{14}$ El caso más conocido es el de la fábrica de Folch y Albiñana, en Sants, que figuraria hasta 1936 como uno de los mayores y más modernos establecimientos del pais. Folch fue además uno de los promotores de las asociaciones de alcoholeros industriales. Véase la descripción de la fábrica y una exposición de sus intereses en el folleto de la Comisión de fabricantes de alcoholes de España (1883).

15 Cámaras de comercio, juntas de agricultura, ayuntamientos, diputaciones, sociedades económicas de amigos del país.

16 En 1893 una coalición de todos los intereses que se habian opuesto a las normas sobre alcoholes de 1892 dio un vuelco a la situación, reformando profundamente la legislación vigente. Por una parte se sustituyó el impuesto por hectolitro y grado en el caso del alcohol vínico por una patente de fabricación, medida que hacía ficticia la protección frente al alcohol de industria al suprimir los teóricos controles del proceso productivo; por otra se unificó el gravamen de los alcoholes no vínicos con un único tipo de 37,5 pts. por hectolitro, admitiendo además los conciertos recaudatorios para los industriales peninsulares. El artículo 46 de la ley de presupuestos, que modificaba de este modo el régimen de los alcoholes, fue aprobado no obstante la oposición de numerosos diputados a este "pacto para el fraude" que mejoraba la posición de los grandes industriales cubanos y desmontaba la protección del aguardiente vínico (extremo que en la fecha no alteraba su posición, pero que daba alas a la expansión de la industria alcoholera). El Congreso aprobó en 1895 una modificación normativa que tendía a poner fin al escandaloso fraude tanto en el impuesto de azuicares como en la parte del de alcoholes que afectaba a los no vínicos, mediante la supresión de los conciertos con la industria. Aun y asi subsistió la exención de hecho de los alcoholes industriales hasta 1900. 
sa de sus intereses, aunque otros grupos más potentes - entre ellos los exportadores de vino, precisados de un alcohol barato- fueron los artífices de la inoperancia en la práctica del principio de protección diferencial de los alcoholes vínicos.

Efectivamente, la amenaza difusa de los otros alcoholes tardó poco en hacerse más concreta. A mediados de los 90 , las azucareras levantaron el vuelo e instalaron amplias destilerías «industriales». La relevancia económica, social y política de los fabricantes de azúcar (un rasgo común del sector en toda Europa), se tradujo además en la presencia permanente de muchos miembros de sus consejos de administración en las cámaras, especialmente la del Senado, y en la formación de un cártel informal en los primeros años de este siglo ${ }^{17}$. La protección al alcohol, que era un subproducto, suponía una medida complementaria. Como la batalla estaba perdida en el terreno de los principios fiscales desde el comienzo, los azucareros centraron sus esfuerzos en hacer que la discriminación en contra del alcohol industrial siguiera siendo lo menos efectiva posible. Su éxito resultó indudable, pues - como hemos señalado- a finales de los 90 se habia consolidado la industria alcoholera.

Por tanto, cuando se presentó el proyecto de ley del ministro Villaverde en 1899 , existia una nueva red de intereses, la de los alcoholeros industriales, muchos menos en número y más homogéneos en sus demandas que el amplio, desorganizado y diverso mundo de los vitivinicultores. El proyecto de Villaverde, un plan ambicioso de permitir la «industrialización» de la actividad en beneficio de la recaudación y el consumo, manteniendo la protección arancelaria, no tuvo sin embargo gran fortuna ${ }^{18}$. En el plazo de «información pública» que se abrió desde el Congreso tras la publicación del documento, volvieron a recibirse en la Comisión de Presupuestos numerosos escritos de agricultores, fabricantes y comerciantes ${ }^{19}$. La resistencia a soportar un impuesto «demasiado gravoso», la idea de que la destilación era un regulador natural del vino, y la convicción de que el Estado debia auxiliar a la vitivinicultura en sentido extenso estaban presentes en la mayor parte de las exposiciones particulares, y todo parece indicar que también en los diputados, que forzaron finalmente la retirada del proyecto.

17 La Asociación General de Fabricantes de Azúcar se fundó en 1906. Llevaban la voz cantante la Sociedad General, la Compañia de Industrias Agrícolas y Ebro. El senador conservador Sánchez de Toca fue el principal valedor de la primera.

18 Sobre los principios de la reforma tributaria de Villaverde, véase Martín Rodríguez (1987, pp. 379-404).

19 ACD, SG, Leg. 312, Exp. 6. Entre los firmantes abundaban los individuos, siendo las asociaciones raquíticas y de ámbito estrictamente local. 
Pero lo que realmente movilizó a los fabricantes de alcohol fue el anuncio en 1903 de un proyecto de ley de alcoholes bajo el impulso de Osma ${ }^{20}$. Este ministro de Hacienda conservador pretendia hacer efectiva por vía fiscal la protección a los alcoholes vínicos - para favorecer a los intereses vitícolas, inmersos en una gran crisis-, mediante el gravamen de todos los alcoholes pero sobre todo de los industriales, de acuerdo con una tarifa en función de la materia prima empleada ${ }^{21}$. Además, la Ley de Osma estableció dos cuotas distin. tas, una de fabricación y otra de consumo; creó un cuerpo de inspectores; y aumentó las barreras arancelarias a la importación. Frente a Osma, y como veremos que ocurrió en el Parlamento, en los foros «cívicos» el grupo de alcoholeros catalanes adquirió un gran protagonismo. Le sirvieron de plataforma el Instituto Agrícola Catalán de San Isidro (IACSI) y la Federación Agrícola Catalano-Balear ${ }^{22}$. La Unió de Viticultors de Catalunya y las cámaras agrarias de Cataluña y Valencia tuvieron asimismo un papel importante ${ }^{23}$. La oposición a la ley Osma se centró en la doble imposición (de fabricación y de consumo) que ésta preveia. La Comisión de Presupuestos recibió entre 1903 y 1907 una avalancha de críticas y protestas procedentes de ayuntamientos, sindicatos, cámaras agrarias y gremios de Cataluña, La Mancha, Madrid, Andalucía y Valencia-Murcia, además de los alcoholeros industriales, que aparecian formando un frente común ${ }^{24}$. Lucas Garzón fue el principal portavoz de los industriales, como presidente de la Sociedad Patronal de Gremios de vinos, aguardientes, alcoholes y licores ${ }^{25}$. Los «agentes económicos» del alcohol parecían estar de

20 ACD, SG, Leg. 340, Exp. 47.

21 El gravamen generalizado de todos los alcoholes pretendia atajar el fraude consistente en la presentación del alcohol industrial como alcohol vínico, haciendo asi efectivo el control del primero, al que se sometia a una elevada tarifa diferencial.

22 El IACSI se había fundado en 1851. A pesar de su pretensión de representar a la agricultura catalana en su conjunto, los grandes propietarios residentes en Barcelona fueron en todo momento predominantes. Los siete diputados y senadores que integraban el grupo estaban vinculados al Instituto. Una de las figuras más relevantes durante el periodo que nos ocupa fue Manuel Raventós, director del Instituto y de la revista del mismo entre 1907 y 1910. También fueron directores el marqués de Camps e Ignacio Girona. La Federación, creada en 1898, nació de la voluntad del IACSI de crear una organización realmente sectorial bajo su hegemonia.

${ }^{23}$ El predominio de los escritos de individuos o instituciones de Cataluña y Valencia se explica porque, hacia 1904, los mercados reguladores del vino se encontraban alli. La Cámara Agraria de Tarragona se mostró especialmente activa y combativa, en la voz de su presidente, Gregorio Rull (véase Rull, 1916). En esas fechas, todas las instituciones catalanas formaban parte de un bloque común, cuyos ideales expuso Raventós (1903) en una conferencia pronunciada en el IAC. SI. Entre los escritos llegados a la Comisión de Presupuestos destaca el de Girona. ACD, SG, Leg. 340, Exp. 47.

${ }_{24}$ ACD, SG, Leg. 340, Exp. 47, Leg. 357, Exp. 12 y Leg. 358, Exp. 1. El encargado de recoger la información pública fue el diputado demócrata Garcia Berlanga.

25 Y de la que Requena, otro miembro destacado de la cruzada contra el doble impuesto, era 
acuerdo en un impuesto especial, único y módico, y en el fomento de las exportaciones como salida a la crisis del sector.

La protesta surtió efecto. La Ley fue pronto sustituida por una serie de proyectos, para los que también se abrió un plazo de información pública. De los 179 escritos que recibió el proyecto de Amós Salvador en 1905, el más duro fue el de la Comisión de Fabricantes de Licores y Anisados de Cataluña, presidida por Salvador Font, que, amparándose en la situación legal de la industria en el extranjero, proponia un impuesto sobre primeras materias para el alcohol vínico y otro a salida de fábrica para el alcohol industrial y la libertad de transformación y circulación ${ }^{26}$. Los azucareros, por su parte, estaban ocupados con un proyecto de concierto económico que, capitaneado por la potente Sociedad General Azucarera de España, significaba la práctica cartelización «tutelada» del sector ${ }^{27}$. Los alcoholeros vínicos siguieron exigiendo la exclusión del alcohol no vínico del encabezamiento de vinos por la vía fiscal (pues, aunque no se cumpliera la legislación, una RO de 1895 prohibía su empleo) al presentarse el proyecto de González Besada en 1908, que fue aprobado ese mismo año ${ }^{28}$. Al margen de la unificación de las dos cuotas de fabricación que habia establecido Osma, de algunos cambios en los tipos y de la concesión de subvenciones a la exportación, la nueva ley no aportó grandes novedades. El reglamento de alcoholes de 1908 si que alteró sustancialmente la tributación, en la medida en que con la intervención fiscal de las fábricas de alcoholes no vínicos disminuyó - pero ni mucho menos desapareció- el escandaloso fraude hasta entonces existente ${ }^{29}$.

secretario. El Gremio, que era de momento la única organización de ámbito estatal, iría adquiriendo importancia en los años siguientes.

26 ACD, SG, Leg. 358, Exp. 1. Aunque quien más poder de convocatoria mostró fue Garzón, que atacó sin piedad el «concierto» que el ministro Salvador proponia para cobrar el impuesto. Detrás del presidente del Gremio estaban los comerciantes, interesados comprensiblemente en un impuesto único sobre la destilación que declarara exentos los productos derivados del alcohol y liberalizara plenamente su venta (que, según el Gremio, sólo en Madrid ocupaba a 5.000 personas).

27 Véanse las exposiciones presentadas al Congreso por los azucareros en 1906: La crisis azucarera y Sociedad General Azucarera de España (1906).

28 ACD, SG, Leg. 371, Exp. 21.

29 Respecto al nivel de fraude existente bajo la ley Osma, tenemos un testimonio excepcional en la memoria de Cristellys (1907), en la que se cifra en un $99,4 \%$ la ocultación de alcohol en la provincia de León en el periodo 1904-1906. El autor señalaba que prácticamente ninguno de los que figuraban en la matricula de la contribución industrial como alcoholeros dieron de alta sus aparatos destilatorios, y que nadie solicitó permiso para la recepción de aguardientes y alcoholes neutros, lo que implicaba adquirir una patente. Por más que se trate de un caso extremo, no cabe duda de que el volumen de fraude en los años 1904-08 fue elevadísimo, tal y como reconocen las propias memorias de la Dirección General de Aduanas. Una visión de conjunto del fraude en el impuesto de alcoholes entre 1900 y 1936, en Puig Raposo (1994a), pp. 357-366. 
Desde 1914, los rumores sobre un proyecto de monopolio, por una parte, y los proyectos de ley de Bugallal en 1914 o Suárez Inclán en 1915, por otra, volvieron a agitar las opiniones en los sectores vinculados al alcohol ${ }^{30}$. Éstas se manifestaban cada vez más a través de grupos establecidos, contribuyendo de este modo a engrosar las filas de las muchas asociaciones que vieron la luz en España después de $1914^{31}$. Era un fenómeno paralelo - y contrario en sus aspiraciones - a los intentos, en el Parlamento, de crear un grupo vitivinícola estable, y a la eclosión, en las poblaciones vitivinícolas, de la convocatoria de asambleas para implicar a la opinión pública y dar a conocer las nuevas organizaciones ${ }^{32}$. Quizá es atribuible a esta movilización el hecho de que el Estado incorporara a sus objetivos en materia alcoholera el de atender esa «cuestión social" en la que se había convertido la vitivinicultura hispánica.

Cuando en 1916 se presentó el proyecto de monopolio de Alba ${ }^{33}, 250$ entidades de todas las regiones manifestaron su desacuerdo, cuando no su indig. nación, a la Comisión parlamentaria encargada del mismo ${ }^{34}$. Los clamores contra el monopolio eran unánimes, aunque no tanto los que se manifestaban contra el «vino artificial» o la «política confiscatoria» del Gobierno. A los vitivinicultores y alcoholeros se unieron entonces los representantes de una «industria naciente» que también reclamaban la protección de los poderes públicos, la industria cervecera. La movilización era creciente y aparentemente imparable. Los intentos de formación de un partido agrario (con Gasset a la cabeza) o de un grupo parlamentario especifico, aunque acabaron fracasando, parecian alentar la consolidación del movimiento en su vertiente vitivinicola. $Y$ es que los intereses eran, a pie de viña y a pie de fábrica, difíciles de conci-

30 Vease información pública en ACD, SG, Leg. 423, Exp. 4.

31 Y que del Rey (1992) ha llamado «fiebre corporativa», pp. 22 y 685-864.

32 Como la de Falset en 1914, que abrió un periodo de renovada beligerancia de la viticultura frente a las instituciones públicas. Véanse los folletos de la Federación Agricola Catalano-Balear y de la Unió de Vinyaters de Catalunya. Las criticas a la «oligarquia» se fueron haciendo frecuentes en los discursos de apertura de las asambleas, con lo que se añadia leña al fuego de la guerra entre grandes y pequeños propietarios.

${ }_{33}$ El proyecto de Alba estaba inspirado en los principios de los paises contendientes respecto a la movilización bélica de las economias nacionales por parte del Estado. En un nuevo intento de hacer del alcohol un articulo de renta fundamental (pues proponia elevar la recaudación de 15 a 66 millones de pesetas en el plazo de cinco años), Alba diseño un monopolio de venta del alcohol, que gestionaría una compañia arrendataria privada. El documento base tenia mucho de compromiso: favorecía explícitamente la producción de alcoholes vínicos; respetaba la libre circulación y venta de alcoholes compuestos y licores; mantenia los incentivos a la exportación; y apoyaba el uso industrial de los alcoholes desnaturalizados. Lo más revelador del proyecto es que optaba por la fijación administrativa de los precios del alcohol monopolizado, con la doble condición de asegurar que resultara remunerador para los cosecheros de vino y que garantizase un margen de ganancia minimo del $10 \%$ para los productores de alcohol industrial (Alba, 1916).

34 ACD, SG, Leg. 433, Exp. 9. 
liar. Al anunciar en 1921 el diputado Zulueta la muerte de su iniciativa de crear un grupo parlamentario vitivinícola dentro de un nuevo movimiento político agrarista, recordó cuáles habían sido los objetivos de la misma: lograr una mejora en la calidad de los vinos, tratando además de reducir los costes; reformar la ley de alcoholes de modo que los cosecheros pudieran hacer de la destilación un regulador de la producción; mejorar los transportes; y establecer una política de compensación arancelaria. Entre las razones de su fracaso, el diputado mencionaba la escasa articulación de las asociaciones y la persisten. cia del caciquismo ${ }^{35}$.

Tras el fracaso del proyecto de monopolio, se mantuvo el gravamen diferencial de los alcoholes (y probablemente el fraude que limitaba su efectividad), y renacieron las pugnas sobre los usos lícitos de cada tipo de alcohol y los mecanismos de vigilancia ${ }^{36}$. Por su parte, el proceso de organización de la representación de intereses siguió adelante. En los años veinte nacieron la Asociación Nacional de Viticultura e Industrias Derivadas; el Gremio de Tratantes del Alcohol y Productos Derivados; y la Asamblea Nacional Alcoholera. En 1921 se fundó la Revista de Alcoboles, Azúcares e Industrias Derivadas, que bajo la dirección de Blas Vives se autodefinió como portavoz de las industrias cenicientas de la nación. La Revista tenía la difícil misión de conciliar los intereses del alcohol vínico y del alcohol industrial, además de los de industrias subsidiarias como las de licores y perfumes. Se publicaron opúsculos y manifiestos y se celebraron mítines y asambleas en todas las localidades españolas. La más importante fue la Asamblea Nacional de Madrid de 1922, donde se fraguaria la Asociación Nacional de Viticultura e Industrias Derivadas (ANVID) ${ }^{3 i}$. El desarrollo del asociacionismo no cesó con la llegada de la Dictadura, que animó desde las instituciones públicas la creación de corporaciones ${ }^{38}$. Una primera victoria de los «industriales», el RD de 1-9-24 que legaliza-

35 LVE 1.10.1921.

36 En 1913 se habia estudiado la legalización del empleo del alcohol industrial para el encabezamiento de los vinos, aunque la campaña iniciada por la Asociación Viticola de Navarra paró cualquier reforma en dicho sentido. La escasez de las cosechas de vino desde 1910 en adelante debió de dar un fuerte impulso al empleo de los alcoholes industriales en la vinicultura, por lo que se tornaron especialmente «molestas» las facultades otorgadas en 1912 y 1914 a diversas asociaciones y sindicatos agrarios para nombrar «veedores» encargados de hacer cumplir la legislación sobre vinos. En los años 20, el aumento del control público de los flujos de alcohol industrial se convirtio en el objetivo central de los viticultores.

37 Que lideraria bajo la Dictadura Santiago Ugarte, de Bodegas Bilbainas.

38 Para el Directorio Militar, véase la documentación alcoholera que se conserva en el AHN, FC, DM, Caja 212/2. Los documentos recogen el progresivo enfrentamiento que tuvo lugar entre la ANVID de Ugarte (bien relacionado aparentemente con el régimen) y la nueva Confederación Nacional de Viticultores Españoles, que encabezaba Julio Tarín. 
ba el uso del alcohol no vínico para usos de boca, desató el activismo de los viticultores de Cataluña, Valencia, La Mancha y Rioja-Navarra ${ }^{39}$. Ese mismo año se fundó la Confederación Nacional de Viticultores, llamada a convertirse en la principal portavoz del rechazo vitícola de los alcoholes industriales ${ }^{40}$. Ya bajo el Directorio Civil, se integraron en el Consejo de Economía Nacional, la Confederación, la Federación de Destiladores y Rectificadores de Alcohol Vinico, dirigida por Ramón Colomer, la nueva Federación Nacional de Criadores, Exportadores y Almacenistas de Vinos de España y las diversas organizaciones antes mencionadas ${ }^{41}$. Fruto de sus trabajos en este marco fue el Decreto-Ley de 29-4-26, con el que se intentó conciliar a los diferentes grupos por medio de la protección del alcohol vínico -único empleable para líquidos potables-y al tiempo el fomento del uso como combustible de todos los tipos de alcoholes, en particular del industrial. En 1930 se convocó la Conferencia Nacional Vitivinícola, que reprodujo propuestas que en términos generales favorecian de nuevo a los vitivinicolas, dejando en minoria - como era de esperar dada la composición de la Conferencia- las propuestas de los alcoholeros industriales, que iban en la linea de mantener la discriminación fiscal de su producto a cambio de su libre empleo para el encabezamiento, la adquisición de alcoholes por CAMPSA y el aumento de las primas a la exportación. No es por ello de extrañar que la Revista de Alcoholes se mostrara cada vez más severa con lo que en sus páginas se llamaba intervencionismo.

En abril de 1931, por el contrario, esta publicación saludó con cierto entusiasmo la llegada del régimen republicano. El tema de los alcoholes pasó a manos de una Comisión Permanente de Agricultura, Industria y Comercio, que fue la encargada - a través de García Berlanga, hijo y heredero político de uno de los principales defensores del alcohol vínico a principios de siglo- de promulgar el Estatuto del Vino y hacer realidad el Instituto Nacional del Vino. Éstos habían de ser los pilares de un ordenamiento jurídico e institucional «estable» del sector alcoholero ${ }^{42}$. De la eficacia del Instituto sabemos

39 AHN, FC, DM, 212/2, Exps. 18 y 21. La Memoria que el Consejo de Economia Nacional encargó en 1926 recogería muchas de las posturas de las organizaciones.

40 Sobre la Confederación Nacional de Viticultores, y en general sobre la «cuestión de alcoholes», véanse los escritos reunidos en la parte III de Carrión (1974), que configuran una documentada e interesante, pero parcial, visión del conflicto (por cuanto que su autor era uno de los principales animadores de las organizaciones favorables a la protección de los viticultores).

41 1926-1930. Hemos tenido que cubrir este periodo por medio de prensa especializada, como LVE, la Revista y publicaciones del propio Consejo de Economía Nacional o de las organizaciones. Es interesante el folleto que la Unión Alcoholera Española (perteneciente a la Sociedad General Azucarera, y primera productora y comercializadora de alcoholes del pais) publicó en 1926.

42 De acuerdo con los deseos de Chapaprieta. Véase Revista, diciembre 1934, pp. 254-56. 
poco. Pero, gracias a él, el asociacionismo alcoholero logró un reconocimiento público, pues en este órgano regulador de la vitivinicultura en sentido amplio estaban representadas las principales organizaciones: la Confederación Nacional de Viticultores, la Federación de Criadores-Exportadores de Vino de España, la Asociación Nacional de Viticultura e Industrias Derivadas del Vino, la Confederación Nacional de Fabricantes-Exportadores de Aguardientes Compuestos y Licores, la Federación de Destiladores y Rectificadores de Alcohol Vínico de España, la Asociación de Fabricantes de Alcoholes Industriales y la Federación Española de Trabajadores de la Tierra ${ }^{43}$. El Instituto reunía por primera vez a los sectores en pugna (que ya habían logrado organizarse en el ámbito nacional) y nacía con el propósito de regular definitivamente el sector. A partir de ese momento las discusiones abandonaban las cámaras y también la calle, para circunscribirse a esta institución ${ }^{44}$. Un triunfo en toda regla del corporativismo ${ }^{45}$.

\section{EL PARLAMENTO Y LA LEGISLACIÓN ALCOHOLERA 46}

Las cambiantes - y efímeras- soluciones legislativas que hemos esbozado brevemente, se gestaron en el Parlamento hasta 1923. Las Cortes, desde 1888, tuvieron un activisimo papel en la legislación sobre alcoholes. En muchos casos la iniciativa de reforma partió de los diputados $(1889,1893,1899)$; en todos, los proyectos gubernamentales fueron objeto de una transformación profunda en el curso de su tramitación parlamentaria $(1888,1889,1904,1908)$; en varias ocasiones los textos enviados por Hacienda a las Cortes naufragaron en el curso de su tramitación $(1899,1903,1907,1914,1915,1916)$. Informaciones públicas $(1889,1904)$, retiradas de dictámenes, comisiones mixtas Congre-

43 Véanse los decretos de 8-9-32, 4-11-32, 14-1-33 y 28-1-33 y la ley de 26-5-33, que dio luz al Estatuto del Vino. Las asociaciones con representación estan recogidas en los artículos 75 y 76.

${ }_{44}$ En las páginas del Diario de Sesiones de las Cortes de la República se refleja el consenso de las fuerzas presentes que aprobaron sin apenas discusión el Decreto-ley de 1932 y lo convirtieron en Ley el 26-5-1933. Carrión (1974, p. 405) no deja lugar a dudas sobre el sesgo "agrarista» de esta disposición: «después de la Conferencia indicada [la de 1930], el Gobierno nombró una Comisión técnica encargada de recoger estos acuerdos y redactar un Estatuto del Vino, pero fue en realidad la Confederación Nacional de Viticultores la que redactó este proyecto que, estudiado por el Ministerio de Agricultura, dio origen al Decreto de septiembre de 1932m.

45 O, en la tipología elaborada por Cawson (1986), de un determinado tipo de «mesocorporativismo», muy escorado en principio hacia las organizaciones vitícolas.

46 ACD, SG, legs. 232 (exp. 33), 254 (exp. 6), 269 (exp. 69), 293 (exp. 17), 310 (exp. 82), 312 (exp. 6), 340 (exp. 2), 340 (exp. 47), 356 (exp. 9), 415 (exp. 39). 
so-Senado $(1888,1904,1908)$, por más que a cualquier observador actual le pueda resultar extraño, los alcoholes fueron una cuestión de candente actualidad y lograron suscitar una continua y apasionada discusión entre los diputados y senadores desde los años 80 hasta la II República. La intensidad y prolongación en el tiempo del debate sugieren que, fueran cuales fueran las limitaciones de la representación parlamentaria, la clase política en su conjunto no se mostró indiferente respecto a las prioridades económicas de la opinión pública en general y de los sectores agroindustriales en particular ${ }^{47}$. Pero la persistencia del debate en el tiempo no implica la continuidad en la representación, ni geográfica ni política, por más que las referencias a un «grupo parlamentario vitivinícola» fueran constantes.

La negociación del convenio con Francia en 1877 estuvo condicionada por las decisiones de un grupo de diputados y senadores con intereses vitivinícolas, en el que se integraban representantes de Valencia, La Mancha, la comarca de Jerez y Cataluña. Estas cuatro áreas fueron en lo sucesivo las de procedencia habitual de los parlamentarios vitivinícolas, con el añadido más irregular de representantes aislados de otras provincias (en particular Logroñq, Zamora, Burgos y Zaragoza). Desde luego esta distribución geográfica no es nada sorprendente, aunque revela que las regiones en las que existía una industria y un comercio vinícolas autónomos y de ciertas dimensiones estaban sobrerrepresentadas, frente a las dominadas por el campesinado viticultor y la vinificación artesana (Galicia y las cuencas del Duero y del Ebro - salvo Rioja Alta-). El desequilibrio geográfico traducía un desequilibrio entre grupos sociales dentro del sector, que se prolongaba en el monopolio de la representación política de las comarcas viticolas y vinicolas con voz parlamentaria, por parte de la gran propiedad y sobre todo de los bodegueros. Pese al sufragio universal, el falseamiento electoral aseguraba según todos los indicios la ex. clusión de un amplio segmento de la opinión pública. Si no había un mercado de votos, sí que había un intercambio de favores entre los parlamentarios y distintos beneficiarios. Es más, la creciente participación de los diputados en los debates alcoholeros a lo largo del primer tercio del siglo xx, puede ser un indicio del aumento de la dependencia de los diputados respecto a los caciques locales, a medida que avanzó la indocilidad de los distritos y perdió eficacia la imposición de los candidatos por parte del Ministerio de la Gobernación ${ }^{48}$.

47 Frente a lo sostenido por Varela (1978, p. 28), quien, al menos para el periodo 1876-1898, afirma que «los intereses económicos no se filtraban a través del Parlamentom.

48 Véanse, por ejemplo, las consideraciones respecto a la «indocilidad» en los distritos de Castilla-La Mancha de González Calleja y Moreno (1993), päginas 218-219. 
La constancia de las procedencias territoriales de los electos se vio contrarrestada en parte por el cambio en el peso de cada zona en los distintos debates: presencia inalterada de Jerez desde el 77 en adelante, fuerte participación catalana en los 80 y a partir de la Ley Osma, creciente intervención manchega y traslación de las voces valencianas desde los distritos costeros hacia los del interior en la década de 1900, cuando la filoxera apagó asimismo la presencia del Alto Ebro. Pero aún en mayor medida varió la procedencia de los defensores de la causa de la industria alcoholera: hasta la segunda mitad de la década de los 90, antillanos e indirectamente catalanes y levantinos; desde entonces andaluces orientales, aragoneses y castellanos. La estructura cambiante de los intereses afectados por las soluciones a la cuestión de alcoholes y la coyuntura -sobre todo la filoxérica pero también la del comercio exterior- se suman por tanto de una forma nítida, mostrando el dinamismo de la representación de intereses geográfica y socialmente definidos ${ }^{49}$.

Frente a la regularidad geográfica, la adscripción política de los abogados de los sectores afectados por la cuestión de alcoholes fue más variable. La práctica del turno, el cunerismo, el recambio generacional y las incidencias de la vida parlamentaria se encargaron de alterar la representación. Antes de 1898 funcionó sin excepciones significativas el montaje electoral canovista, y fueron escasos los parlamentarios vitivinicolas que estuvieron de forma más o menos continuada en las discusiones de los sucesivos problemas alcoholeros. El duque de Almodóvar del Rio ${ }^{50}$, y el marqués de Mochales ${ }^{51}$ se erigieron en representantes permanentes y reconocidos de la vinicultura de la comarca andaluza, con un reparto peculiar de papeles por cuanto que el primero era librecambista y el segundo uno de los principales proteccionistas de las Cortes. El diputado liberal por la Albaida, Manuel Iranzo Benedicto 52, fue el portavoz de las posturas vitícolas, y en general agrarias, valencianas. Otro liberal, diputado por Daimiel, Emilio Nieto Pérez ${ }^{53}$, defendió a los productores manchegos. Similar era la posición del conde de Retamoso, diputado por Tarancón ${ }^{54}$. El

49 Desde otra perspectiva, las desapariciones y reapariciones de äreas regionales del escenario del debate demostraban en unos casos la personalización y en muchos la inmediatez de la atención de la representación parlamentaria a los problemas económicos.

so José Manuel Sánchez Gutiérrez de Castro, diputado liberal por Priego de 1879 a 1883 y por Jerez de 1886 a 1905, sucedido por su hijo José R. Sánchez Hoces en 1907, elegido por Jerez.

51 Miguel López de Carrizosa y de Giles, diputado y senador conservador jerezano desde 1891 hasta 1907 . Véanse las numerosas referencias a la labor de Mochales en Arana (1988).

52 De 1893 a 1905.

33 Entre la legislatura de 1881 y la de 1901.

54 José Muñoz y Garcia Luz (1893-1901). 
tarraconense Juan Cañellas y Tomás 55 y Enrique Bushell y Laussat, diputado por Pego y Valencia desde 1881 hasta su muerte, llevaron al Congreso la voz de los exportadores de Tarragona y Alicante. Por su parte, el conservador romerista Francisco Bergamín y García, diputado por Campillo (Málaga) entre 1886 y 1910 , era reconocido como uno de los más explícitos azucareros y por ende el portavoz de los alcoholeros de melazas ${ }^{56}$.

Estos casos se salieron sin embargo de la regla: la coincidencia de una presencia continuada en el Congreso y la participación en los debates de alcoholes se vio en general limitada por los propios mecanismos de elección parlamentarios. Es probable que también lo estuviera por la asociación entre liberalismo-republicanismo y la cúspide del sector, exportadores y criadores, puesto que las leyes más importantes del XIX (las de 1892 y 1893) y todas las del Xx (proyectos fallidos de 1900 y 1903, leyes de 1904 y 1908) fueron enviadas a Cortes de mayoria conservadora.

Tras la crisis del 98, se iniciaron las rupturas de la hegemonía dinástica en algunos distritos. Desde 1903 pasaron a estar presentes en las Cortes de modo bastante estable los republicanos Nougués, por Tarragona, y Zulueta, por Vila. franca del Penedès, junto con el liberal primero y demócrata después Fidel García Berlanga 57, y en 1907 lograron su escaño varios destacados propietarios con intereses viticolas, asi como empresarios y lideres del sector, en las filas de Solidaritat Catalana (Girona, Raventós, Macià). Todos ellos conformaron el núcleo decisivo en los reiterados intentos de construcción de un grupo vitivinícola estable hasta 1923. En La Mancha, la región en la que la vitivinicultura avanzó en mayor medida desde los años 90 , la subsistencia de las prácticas electorales típicas de la Restauración favoreció la inestabilidad de los representantes: Tomás Romero, republicano de Alcázar de San Juan, y el empresario vasco con negocios en Valdepeñas Santiago Ugarte fueron en distintos momentos la voz de los bodegueros manchegos en el Congreso, por más que la figura más constante fuera el cacique conservador toledano Quintin Escobar. En cualquier caso, si el factor permanente fuera de las comarcas catalanas fue el territorial y no el personal o el partidista, parece razonable suponer que imperaba la lógica del favor colectivo al distrito - fuera cual fuera el contenido real de esa defensa territorial- más que la del favor personalizado, la disciplina de partido o la adscripción ideológica.

ss Diputado por Vendrell entre 1881 y 1905.

56 De hecho en la provincia de Málaga tres distritos (Antequera, Campillos y Vélez y Torrox) fueron reductos permanentes de tres personajes ligados al azúcar (Romero Robledo, Bergamin y Larios), aunque este ütimo no participo abiertamente en los debates del Conureso (Arcas (1985)).

5) Diputado por Requena en varias legislaturas desde 1901 y hasia su tallecimiento en 1914. 
Únicamente se separaron de esta posición los diputados republicanos y solidarios, que accedieron al parlamento tras romper el control desde arriba del proceso electoral en Cataluña, y que por su dependencia respecto a los votos populares y su papel de oposición, tenían que actuar de manera más decidida en pro de las opiniones imperantes entre su electorado, social e ideológicamente diferenciado, en el que los rabassaires y la pequeña burguesía de algunos centros vinícolas tenía un peso importante.

Ello no obsta para que el favor colectivo, lo más parecido a una lógica de maximización de votos ${ }^{58}$, se sumara en algunos casos a otras lógicas, como la de la implicación personal o la representación de grupos sectoriales supralocales ${ }^{59}$. Así, desde los años 80 hasta 1923, fue constante la presencia en las Cortes de distintos diputados y senadores que eran propietarios vitícolas y empresarios vinícolas importantes (Escobar, García Berlanga, González-Conde, Martínez Acacio, Miró, Raventós, Girona, Soler, Burgos, Montiel) o comerciantes dedicados a la exportación (Bushell, Mainer) o se sentaban en consejos de administración o de dirección de las azucareras (Cortina, Llorente).

No era fácil que voces tan dispares actuaran con coherencia. Unos defendían a los grupos de interés más influyentes de sus distritos o de sus lugares de origen ${ }^{60}$. Los demás se representaban a sí mismos o a otros de su clase econó-

58 Maximización de apoyos entre los notables del distrito. El caso más destacado de este tipo de trayectorias fue el del diputado cunero por Daimiel Emilio Nieto, que trabajaba como abogado en Madrid y tenia escasos contactos con la población manchega, pero que a través de sus influencias administrativas y sus intervenciones parlamentarias, llegó a ser «el hacedor de favores» del distrito, convirtiéndose en candidato de las fuerzas vivas locales (Barreda, 1986). Curiosamente, su sucesor en las legislaturas de 1903 y 1904, el conservador Antonio García Noblejas, también mantuvo una activa participación en los debates de alcoholes. Algo similar hizo al diputado cunero demócrata por la circunscripción de Alicante, Francos Rodríguez, que se dedicó activamente a la representación de los intereses de la burguesía comercial vinculada a los negocios portuarios en la ciudad (Forner, 1990).

59 Organizados como la Asociación de Agricultores de España (con Bayo, Eza...), la Federación Agrícola Catalano-Balear (Girona, Raventós, marqués de Camps...), la Federación Agricola de Levante (Iranzo), diversas camaras de comercio (muy especialmente las de Reus, Tarragona, Alicante, Málaga)..., pero también informales como los azucareros clientes del bufete de Bergamin, los alcoholeros gallegos que hablaban por boca del diputado liberal Vincenti o los minoristas de aicoholes de Madrid, reunidos en la asociación «La viña», cuyo abogado era el diputado Alfonso Senra - según se afirmaba en LVE: 15-11-1918, núm. 182.

60 Las «recomendaciones» de algunas exposiciones llegadas a la Cámara eran una práctica habitual, tal y como se puede comprobar en los expedientes de todos los proyectos (ACD, SG, leg. 312, exp. 6; leg. 340, exp. 2; leg. 340, exp. 470). Subrayamos que se hacia sólo con algunos, lo que convertia la recomendación en algo más que una presentación formal y sin contenido politico. 
mica o incluso a terceros ${ }^{61} \mathrm{o}$ bien ambas cosas a la vez ${ }^{62}$, además de verse afectados en distinto grado por sus lealtades políticas y tener una presencia muy inestable en las cámaras y en los debates a consecuencia del propio sistema turnista. En la práctica, cada polémica de alcoholes en el Parlamento fue una polémica distinta, aunque cabe hacer tres observaciones de carácter general.

La primera es que la escasa representación parlamentaria de los intereses de los pequeños viticultores, mayoritarios en el sector, hizo que el Ministerio de Hacienda ${ }^{63}$ se convirtiera en la instancia inicialmente más cercana a sus posiciones. Tras esta defensa del interés público, en el sentido de interés del mayor número, se hallaban probablemente la percepción de la correlación de fuerzas en el Parlamento y de las dificultades técnicas de controlar la destilación rural en pequeña escala, por lo que un mayor gravamen y sobre todo un mayor control del alcohol no vinico equivalia a mayores ingresos. La segunda es relativa a la mecánica de los debates, que guardó en el tiempo ciertas similitudes. Los grandes grupos de interés definidos alrededor de cada proyecto de reforma contaban con uno o más líderes, que recibían por una parte el apoyo de sus amigos políticos y por otra el de parlamentarios de otras adscripciones. Se trataba de lograr la máxima diversidad política y geográfica entre estos últimos, a la búsqueda de una apariencia de respaldo suprapartidario y suprarregional (en una clara estrategia de globalización del problema). Cada grupo de enmendantes así construido aparecía conectado con los demás por medio del apoyo de una serie de diputados-puente, trazando así las grandes lineas de consenso entre las posturas representadas en la Cámara. Por último, que el consenso creado sobre la base de los representantes territoriales era un con-

61 Y lo hacian de forma abierta, presentandose como portavoces de los alcoholeros gallegos (Vincenti en el debate de la ley de 1888), de las cámaras tarraconenses (Marín también en 1888), de los exportadores de Levante y Cataluña (Cañellas en 1889), de fabricantes de Vilafranca del Penedès (Lostau en 1895), de intereses de mítines de Jumilla y Cariñena (Retamoso en 1895).

62 La coincidencia de poder politico y poder económico era notable en muchos distritos viti. vinicolas, en los que los grandes bodegueros controlaban personal o indirectamente la representación en Cortes. Asi ocurria en el Condado onubense (como sabemos en detalle gracias al trabajo de Peña, 1993), pero también en La Rioja, en el Marco de Jerez, el Penedès.

${ }^{63}$ Más concretamente, Puigcerver, Osma y Alba. El senador Rosell se hacia eco de esta situación en un discurso ante la Cámara en 1904: “Yo pretendo llevar la voz, sin que nadie me haya dado su representacion, de los pequeños propietarios viticolas, porque, Señores Senadores, habréis observado todos, durante la agitación que ha precedido a la aprobación de esta ley y du. rante la propia discusión de la ley misma, que se han agitado en Madrid toda clase de intereses. Aqui han venido Comisiones numerosísimas de exportadores de vinos; aqui han venido Comisiones importantes de comerciantes de vinos; aquí han venido Comisiones de fabricación de licores y de alcoholes de todas clases. El pobre agricultor, y sobre todo el pequeño agricultor, como siempre, no ha tenido ni ha contado con más apoyo ni protección que la del digno ministro de Hacienda» (DSC, S, leg. de 1903, p. 3079). 
senso negativo, que tendía a difuminar los proyectos ministeriales y a privarlos de su coherencia interna. La protección frente al exterior (fijada en 1892), unos mínimos de recaudación que estaban determinados por los últimos ingresos obtenidos, la discriminación tarifaria en favor del alcohol vínico ${ }^{64}$ y la limitación de la carga fiscal soportada por el sector ${ }^{65}$, eran los elementos decisivos. El resultado último era tanto una limitación de los ingresos públicos como la ineficacia de la proclamada protección diferencial del alcohol vínico por la vía fiscal, que coexistía con una posición insegura, en términos jurídicos, de los alcoholeros industriales.

La regulación que la clase política y la Administración ofrecian era ineficaz para todos los intereses implicados, por más que sobre el papel se asegurara una posición de privilegio en el mercado de los alcoholes vínicos. Ante esta realidad se rebelaron todo un conjunto de instancias directamente vinculadas al sector vitivinicola, a lo largo de las décadas de 1910 y de 1920. La creación de un grupo parlamentario vitivinícola, permanente y suprapartidario, fue una de las iniciativas defensivas pensadas en las organizaciones corporativas del sector que contaban con representación parlamentaria. Ahora bien, pese a la constitución de coaliciones temporales de diputados, el proyecto resultó ser un fracaso. A las peculiaridades del sistema electoral, con el falseamiento de la voluntad de los electores y la autonomía de los parlamentarios repetidamente denunciada por La vinicultura española ${ }^{66}$ y por algunos de los diputados no dinásticos (Zulueta, Romero), se sumaba la absoluta imposibilidad de presentar un frente unitario de agrarios e industriales, de grandes y de pequeños, de exportadores y de vendedores en el mercado interior; la inexistencia, en suma, de unos intereses «vitivinícolas» en abstracto y en menor medida todavía de unos intereses «alcoholeros». El problema no era tanto la falta de acuerdo entre grupos sobre acciones positivas, esperable en un medio tan diverso, cuanto la incapacidad del ejecutivo y del legislativo para enunciar una solución política diferente a la mera resultante de los intereses heterogéneos representados en las Cortes. No se trataba de que el Parlamento fuera inoperante, sino de que impedia una efectiva autonomia de la acción regulatoria del Gobierno, al imponerle un imposible acuerdo entre intereses contrapuestos ${ }^{67}$.

${ }^{64}$ Que sólo estuvo en peligro en el proyecto de Villaverde. Los azucareros lograron asimilarlo al de melazas y una coalición de andaluces, baleares y catalanes, al de higos. fraude.

"S Merced a la reducción de los instrumentos estructurales y de vigilancia para el control del

66 Véase por ejemplo el artículo «¿Y el grupo parlamentario vitivinícola?», en LVE, 1-12 66 Véase por ejemplo el artículo « ¿Y el grupo parlamentario vita
(1918), núm. 135, donde se señala que «eso de la representación nacional es una pura y completa
farsa».

67 En este sentido queda confirmada la visión de del Rey (1992). 


\section{BALANCE Y CONCLUSIONES}

Nuestro estudio sobre la regulación sectorial y la acción de grupos de interés en la industria alcoholera es, simplemente, un ejercicio de investigación en el campo, poco explorado en los últimos años, de las relaciones entre economía y política. De este ejercicio no se puede desprender otra cosa que un balance provisional, que deseamos organizar alrededor de cuatro grandes «observaciones».

La primera hace referencia a los grupos de interés. De nuestro análisis se infiere que la representación de intereses gozó de una elevada autonomía respecto a los intereses representables. El hecho de que los cauces empleados variaran en el tiempo con un ritmo que no determinó la coyuntura sectorial ni los cambios estructurales de la vitivinicultura o la industria alcoholera es importante porque las formas adoptadas por la representación de intereses explican en buena parte el contenido y la eficacia de las demandas expresadas. De la movilización desde instancias político-administrativas o controladas por la Administración, y vinculadas a la propiedad de la tierra, se pasó entre la década de 1890 y los primeros años del siglo $\mathrm{xx}$ a la movilización mediante un nuevo tipo de asociaciones "privadas», separadas del Estado. Unas peticiones formuladas en términos territoriales - aunque socialmente sesgadas- son características de la cuestión de alcoholes en el siglo xix. El punto de encuentro, de evidente trascendencia pero muy alejado del nivel de regulación solicitado, fue la exclusión de los alcoholes extranjeros. Tras el cambio de siglo, la competencia de asociaciones «privadas» y los cambios sectoriales obligaron a superar ese nivel de intervención política y a ordenar prioridades, tanto más a medida que creció - sobre todo entre 1914 y 1923 - la diferenciación y fragmentación de los intereses en pugna.

La segunda observación alude a cómo se enfrentó el Parlamento a la obligación, impuesta por la opinión pública, de regular el crecimiento económico. Frente a la multiplicación de las demandas por parte de asociaciones definidas en términos de intereses económicos cada vez más restringidos y precisos, el Congreso se mostró incapaz de articular políticas sectoriales con fines jerarquizados, aunque sí dedicó un tiempo creciente a la discusión de las cuestiones de «intereses materiales» vinculados al alcohol. El falseamiento de las elecciones y la cooptación de buena parte de los diputados, más la destrucción de los partidos de notables - y la minima presencia parlamentaria de agrupaciones políticas estables de nuevo cuño-, impidieron que las Cortes respondieran a la mutación y ampliación de la burguesía y las clases medias y al desarrollo y diversificación del aparato productivo. 
Llegamos por ello a la tercera observación: el ejecutivo se convirtió en la única instancia capaz de definir intereses públicos, industrializadores (Villaverde) o agraristas (Osma; en menor medida González Besada), sobre el telón de fondo de la apuesta por incrementar la recaudación fiscal. Las propuestas ministeriales se enfrentaron en todos los casos a un haz de enmiendas, cuyo éxito no dependia del apoyo de los partidos o de grupos regionales, sino precisamente de la creación de una apariencia de respaldo suprapartidario y suprarregional, con lo que el proceso legislativo tendió a vaciar los proyectos de sus elementos novedosos y de su coherencia interna. Se impuso la inercia normativa, un conservadurismo que otorgaba especial ventaja a la primera solución adoptada. La impotencia reformista desplazó la «captura» de protecciones no arancelarias para uno u otro subsector y la definición global de límites y poderes de mercado, a ámbitos no reglados como la corrupción administrativa y el fraude fiscal y sanitario ${ }^{68}$. De ahi que no se estableciera un orden de objetivos politicos para el funcionamiento de los mercados ni se especificara un proyecto de desarrollo económico de la vid, la vinificación y la destilación, de acuerdo con los supuestos implícitos en la adopción de aranceles protectores. Hubo que esperar hasta la Dictadura y, sobre todo, hasta la República, para que el pie invisible se convirtiera en mano visible.

La cuarta y última observación es la de carácter más general. Ya hemos señalado que los modelos basados en la racionalidad de los demandantes de regulación, la asimilación plena de la decisiones políticas a una mercancía y el análisis parcial (englobables bajo la etiqueta de public choice) son en nuestra opinión poco aptos para explicar el funcionamiento de la política real. Ciñéndonos a nuestro campo, no cabe duda de que la vitivinicultura resultó en términos normativos y durante el periodo 1887-1936 la gran beneficiaria de la regulación pública. La protección de la industria alcoholera se acometió entre 1888 y 1892 de acuerdo con los intereses aparentemente mayoritarios en la vitivinicultura y con las exigencias de unas relaciones comerciales internacionales vertebradas por la exportación del vino. Por su parte, el régimen fiscal del alcohol se fundó en la discriminación positiva del alcohol vínico durante casi cincuenta años. ¿Se puede decir entonces que el grupo más amplio, de mayores dificultades organizativas y más heterogéneas estructuras productivas, logró un claro triunfo? No, al menos hasta la II República. El fraude aseguró que la hegemonia de los viticultores en el terreno de la definición del interés público plasmado en la legislación, se tradujera en una realidad mucho más equilibra-

68 Véase a este respecto Puig Raposo (1994a) y Pan-Montojo (1994a). En general sobre esta cuestión es interesante la consulta de muchos de los articulos reunidos en «El fraude fiscal en la historia de España» (1994). 
da entre todos los intereses sectoriales en juego. Cabe preguntarse si la suma de controles laxos en el ámbito fiscal y sanitario y unos principios generales «agraristas» no era la mejor combinación posible para los bodegueros que no fabricaban alcohol, eran clientes y no suministradores de la industria alcoholera, rechazaban la reforma de la distribución de cargas fiscales y se beneficiaban en términos de imagen de las garantias inoperantes de la bondad y naturalidad de su producto. Es decir, si el aparente éxito del grupo más amplio y más disperso, no encubre el de un subgrupo de gran peso en el Parlamento (con bajos costes de organización y altos beneficios relativos). Quizá en ciertos momentos fuera asi, pero los bruscos cambios coyunturales y estructurales del sector, la diferenciación interna de los bodegueros y la dependencia de la legislación respecto a su trayectoria anterior ${ }^{69}$, el inmovilismo parlamentario que hemos constatado, impiden hablar de una hegemonía permanente de los bodegueros (extremo que confirman sus cambiantes formas de organización, alianzas y demandas).

La considerable distancia que separaba el pais real y el pais legal, y que desde luego no ignoraban ni reguladores ni regulados, no nos debe llevar a desdeñar las implicaciones del triunfo de los viticultores en el terreno de los grandes principios normativos. Prueba de su importancia fueron los reiterados intentos por parte de los alcoholeros industriales, de acabar con la prohibición de emplear su producto para usos de boca y de atenuar o eliminar la discriminación fiscal que sufrian. La incapacidad del Estado liberal para imponer una legislación tributaria eficaz dio lugar a una solución insatisfactoria para todos los grupos afectados por la cuestión de alcoholes ${ }^{70}$, pero además a una solución profundamente inestable y desigual y muy dependiente de las correlaciones locales de fuerza, y que desde luego no favorecía ningún proyecto inversor de medio plazo. Dos intereses fueron gravemente lesionados por el camino: el recaudatorio y el de los consumidores. En España, efectivamente, la recaudación de alcoholes proporcionó cifras muy bajas ${ }^{71}$ y las bebidas alcohólicas resultaron más caras y de calidad inferior a las esperables, respectivamente, de la libre destilación y de una política de control riguroso de los productos.

69 Una inercia política que podría admitir la comparación con la inercia geográfica modelizada por Krugman (1992).

70 En la línea de lo que sugiere Peltzman (1976) que ocurriría con beneficios y costes medibles. La posibilidad de medir una y otra variable presenta sin embargo dificultades insalvables - para nosotros y para los coetáneos, de ahi el frecuente carácter errático de sus demandas-, en una situación en la que el fraude tenía unas dimensiones tan amplias y las estrategias de defraudación unos costes tan variables en el espacio y el tiempo.

11 Hacia 1913 en España los ingresos del impuesto de alcoholes equivalian al $2 \%$ de los ingresos totales y en Francia al $13,5 \%$, con sistemas tributarios similares. 
Estas consideraciones ponen en nuestra opinión de manifiesto la escasa capacidad explicativa de modelos que identifican a priori los objetivos económicos, agregan intereses de empresarios individuales y consideran lo que es una realidad política inestable y cambiante, el marco institucional (con componentes tan etéreos como la «cultura política»), como un dato ${ }^{72}$. Enlazamos asi con nuestra reflexión introductoria de este trabajo. El debate entre agraristas e industrialistas, que es en definitiva un debate sobre la acción de los grupos de interés en la economía de la España liberal, precisa de nuevas investigaciones desde dentro de los subsectores agrarios e industriales. Tales investigaciones, necesariamente dinámicas, deberían comprender las transformaciones, exógenas y endógenas, que han tenido lugar en las instituciones donde actúan los grupos de interés. Aunque esto supusiera una pérdida de elegancia formal, se obtendría a cambio una visión histórica plena de la génesis y desarrollo de la intervención pública en la economia, en un espacio y un tiempo concretos, tarea en la que las teorías supuestamente atemporales, aespaciales y supraculturales deben servir de acicate y no de molde.

\section{ABREVIATURAS}

ACD Archivo del Congreso de los Diputados

AHN Archivo Histórico Nacional

AMA Archivo del Ministerio de Agricultura

DSC, CD Diario de Sesiones de las Cortes, Congreso de los Diputados

DSC, S Diario de Sesiones de las Cortes, Senado

LVE La vinicultura española

RD Real Decreto

RO Real Orden

72 No cabe además olvidar que, como reconoce Stigler (1975, p. 140), el contraste de las im. plicaciones de las teorias planteadas sobre estas bases resulta especialmente dificil, al menos -añadimos nosotros- en ausencia de una definición operativa y no tautológica de la utilidad a maximizar por cada participante. 


\section{BIBLIOGRAFÍA}

ALBA, Santiago (1916): Un programa económico y financiero, Madrid.

Arana Perez, Ignacio (1988): La Liga Vizcaina de Productores y la política económica de la Restauración, Bilbao, Caja de Ahorros Vizcaina.

ArCas Cubero, Fernando (1985): El republicanismo malagueño durante la Restauración (1875-1923), Córdoba, Ayuntamiento de Córdoba.

BANTl, Alberto Maria (1990): Terra e denaro, Venecia, Marsilio.

Barreda Fontes, José María (1986): Caciques y electores. Ciudad Real durante la Restauración 1876-1923, Ciudad Real, Instituto de Estudios Manchegos.

CABRERA, Mercedes (1983): Las organizaciones patronales durante la II República, Madrid, Siglo XXI.

Carnero, Teresa (1980): Expansión vinicola y atraso agrario, 1870-1890, Madrid, Ministerio de Agricultura, Pesca y Alimentación.

CARrión, Pascual (1974): Estudios sobre la agricultura española, Madrid, Ediciones de la Revista de Trabajo.

Cawson, Alan (1986): Corporatism and Political Theory, Londres, Basil Blackwell.

Comisión de fabricantes de alcoholes en España (1883): La industria alcobolera en España, Barcelona, Establecimiento tipográfico de los sucesores de N. Ramírez y Cía.

Comisión Extraparlamentaria para la Transformación del Impuesto de Consumos (1910): Datos estadísticos, Madrid, Imprenta de Sucesora de M. Minuesa de los Ríos.

Consejo de la Economia Nacional (1926): Memoria de la Comisión encargada del estudio de la producción vitivinicola, Madrid, Gráficas Reunidas, S. A.

Cuentas del Estado español. Estadistica de los presupuestos generales del Estado, 1850-1957, Madrid, Instituto de Estudios Fiscales.

El alcobol y el Consejo Regional de la «Unió de Vinyaters de Catalunya» (1915), Tarragona, Imprenta de José Pijoan.

«El fraude fiscal en la historia de España», número monográfico de Hacienda Pública Española, I.

Elias de Molins, José (1904): Algunos datos y consideraciones sobre los trigos y vinos en España, Barcelona, Imprenta barcelonesa.

EsCudero Gutierrez, Antonio (1994): «El fraude fiscal en la minería española (18761935)», Hacienda Pública Española, I, pp. 321-342.

Forner, Salvador, y Garcia Mariano (1990): Cuneros y caciques, Alicante, Patronato municipal del V Centenario.

Fraile Balbin, Pedro (1991): Industrialización y grupos de presión. La economía política de la protección en España, 1900-1950, Madrid, Alianza.

Gonzalez Calleja, Eduardo, y Moreno Luzón, Javier (1993): Elecciones y parlamentos. Dos siglos de bistoria en Castilla-La Mancha, Toledo, Servicio de Publicaciones de la Junta de Comunidades de Castilla-La Mancha/Cortes de Castilla-La Mancha.

Informe de la Cámara Agrícola Oficial de Tarragona sobre alcoboles (1914), Barcelona, Establecimiento tipográfico de Pedro Ortega.

Informe que, por acuerdo de la Cámara Agrícola Oficial de la provincia de Tarragona, emite su presidente en la información pública sobre el proyecto de ley relativo al Monopolio de Alcoboles (1916), Barcelona, Establecimiento tipográfico de Pedro Ortega.

Krugman, Paul (1992): Comercio y geografía, Barcelona, Antoni Bosch. 
La crisis azucarera (1906), Zaragoza, s.i..

Malatesta, Maria (1989): I signori della terra, Milán, Franco Angeli.

MarTín Rodriguez, Manuel (1987): «Los impuestos de fabricación de Fernández Villaverde: una valoración económica actual», en Hacienda Pública Española, núm. 87, pp. 379-404.

MENY, Ives, y Toenig, Jean-Claude (1992): Las politicas públicas, Barcelona, Ariel.

Olson, Mancur (1977): The Logic of Collective Action. Public Goods and the Theory of Groups, Cambridge, Cambridge University Press.

(1986): Auge y decadencia de las naciones, Barcelona, Ariel.

Palafox, Jordi (1992): Atraso económico y democracia. La Segunda República y la economía española, 1892-1936, Barcelona, Crítica.

Pan-Montojo, Juan (1993): El Estado y la vid. Los origenes de la política agraria a través de la vitivinicultura, 1847-1923, Madrid, Ediciones de la Universidad Autónoma de Madrid.

- (1994a): La bodega del mundo. La vid y el vino en España, 1800-1936, Madrid, Alianza. (1994b): «El vino y la política comercial en la Restauración», en Agricultura y Sociedad, núm. 72, pp. 167-203.

Peltzman, Sam (1976): «Toward a more general theory of regulation» en Journal of Law and Economics, vol. 19, núm. 2, pp. 211-244.

Peña Guerrero, María Antonia (1993): El sistema caciquil en el provincia de Huelva. Clase política y partidos (1898-1923), Córdoba, Ediciones la Posada.

Piqueras Haba, Juan (1981): La vid y el vino en el País Valenciano, Valencia, Alfons el Magnànim.

Puig RAPOSO, Núria (1994a): «El fraude en la industria alcoholera, 1900-1936» en «El fraude fiscal en la historia de España», número monográfico de Hacienda Pública Española, 94/I, pp. 357-366.

— (1994b): «Modernización y regulación. La industria alcoholera española, 18561953», en NADAL, J., y CATALAN, J: La cara oculta de la industrialización en España. La modernización de los sectores industriales no líderes, Madrid, Alianza, pp. 99-126.

PUjol i ANDREU, Josep (1984): «Les crises de malvenda del sector vitivinicola català entre el 1892 i el 1935", Recerques, núm. 15, pp. 57-78.

Raventós, Manuel (1903): Ponencia acerca de la tributación de alcoboles, Barcelona, Establecimiento tipográfico de Pedro Ortega.

REY REGUILLO, Fernando del (1988): «Los intereses vitivinícolas manchegos en una coyuntura de cambio. Datos para el estudio de un grupo de presión (1917-1923)», I Congreso de Historia de Castilla-La Mancha, tomo IX, Talavera, Junta de Comunidades de Castilla-La Mancha.

(1992): Propietarios y patronos. La política de las organizaciones económicas en la España de la Restauración (1914-1923), Madrid, Ministerio de Trabajo y S. S.

Rull, Gregorio (1916): El gravamen de los alcoboles, Barcelona, Establecimiento tipogräfico de Pedro Ortega.

SerRano SAnZ, José María (1987): El giro proteccionista de la Restauración, Madrid, Siglo XXI.

Sociedad General Azucarera de España (1906): Exposición presentada a la Comisión de Presupuestos del Congreso de los Diputados, Madrid, Imprenta de hijos de M. G. Hernández.

Sociedad de fabricantes y Comerciantes de Anisados y Licores de Cataluña (1916): Informe sobre el proyecto de ley de la Renta del Alcohol, Barcelona. 
Solé Villalonga, G. (1967): La reforma fiscal de Villaverde, 1899-1900, Madrid, Editorial de Derecho Financiero.

STIGLER, George J. (1975): The Citizen and the State. Essays on Regulation, Chicago y Londres, The University of Chicago Press.

TORTELLA, Gabriel (1994): El desarrollo de la España contemporánea. Historia económica de los siglos XIX y XX, Madrid, Alianza.

Unión Alcoholera Española (1926): Concepto de las causas productoras de la crisis vitivinicola actual y de la Memoria presentada al Consejo de Economía por la Comisión nombrada por el Gobierno para su solución, Madrid, Imprenta de Vicente Rico.

VARELA ORTEGA, José (1978): «El proteccionismo de los trigueros castellanos y la naturaleza del poder político en la Restauración», en Cuadernos Económicos de ICE, núm. 6, pp. 7.60 . 